Check for updates

Cite this: RSC Adv., 2017, 7, 54668

\title{
Silica film deposited on diamond-structured polymer microlattices by dip coating
}

\author{
Fang Wei, (D) ab Yongfeng Zhou, ${ }^{\text {ab }}$ Qinglin Yang, ${ }^{\text {ab }}$ Lin Guo $^{\text {ab }}$ and Lei Jiang ${ }^{\text {ab }}$
}

The specific strength of lightweight cellular materials mainly depends on their structure and composition. In this study, polymer microlattices with diamond structures were fabricated by 3D printing. Then, silica materials with high strength were covered on the polymer microlattices using a dip-coating method, and we obtained polymer $/ \mathrm{SiO}_{2}$ microlattices, which had the properties of low density, high compressive strength, and good thermostability. Moreover, three types of silica films with different thickness, i.e., $10.1 \mu \mathrm{m}, 18.3 \mu \mathrm{m}$, and $23.6 \mu \mathrm{m}$, were deposited on the microlattices. The compressive strength of the polymer $/ \mathrm{SiO}_{2}$ microlattices can be improved upon increasing the thickness of the silica coating. The thermostability of the polymer can be enhanced after coating with the silica materials and was improved more dramatically with a thicker coating. Light hollow-tube $\mathrm{SiO}_{2}$ microlattices with a density of $14.7 \mathrm{~kg} \mathrm{~m}^{-3}$ were also fabricated by calcining the polymer template at high temperatures.

Received 22nd August 2017

Accepted 13th November 2017

DOI: $10.1039 / \mathrm{c} 7 \mathrm{ra09297k}$

rsc.li/rsc-advances that make up the architecture are polymers. There were three reasons to select polymers over other materials. First, polymers have a wide range of applications in research. Thus, we wanted to investigate that the changes in their mechanical properties and thermal stability after being coated using a low-cost and simple method, to expand their applications. Second, polymers can be calcined, and we aimed to construct a perfect hollow tube structure to investigate its functionality to obtain materials with a perfect combination of mechanical structure and function. Ceramics are materials with high strength in inorganic materials. Third, the polymer materials that we used to fabricate the architecture by 3D printing have better precision, ${ }^{34,35}$ which is beneficial for the subsequent coating process, and it is easier to obtain a smooth coating. Silica is an important inorganic material, which belongs to atomic crystal and possesses excellent mechanical and thermal properties due to the diamond-like structure formed by the $\mathrm{Si}-\mathrm{O}$ covalent bonds. ${ }^{36}$ To protect the surface of the polymeric materials and improve other properties of the materials, a ceramic film can be coated on the surface of polymeric materials to obtain new types of composite, which have attracted significant attention; moreover, some meaningful research has been carried out in this regard recently. ${ }^{37-41} \mathrm{~A}$ biomimetic study has shown that hybrid materials consisting of an inorganic shell and a polymer core exhibit higher mechanical performance than the individual constituent materials. Therefore, by fabricating polymer/ceramic composites, the materials can significantly improve their mechanical properties. ${ }^{25,42-46}$

Surface coating technology is an important way to modify the surface of materials, which plays an important role in improving material usability, expanding the scope of a material and realizing the functional combination of materials. There are many ways, such as electroless plating, 1,5,22,24,26,29,47

\begin{abstract}
${ }^{a}$ Key Laboratory of Bio-inspired Smart Interfacial Science and Technology of Ministry of Education, Beijing, China.E-mail: yangql@buaa.edu.cn

${ }^{b}$ School of Chemistry and Environment, Beihang University, Beijing 100191, China structural htrongly on the cell geometry including shape, size, and produce structured materials, the diamond structure is preferred attaining material with high strength and low density du and strong stability to resist deformation..$^{11,32,33}$

The strength of lattice materials not only depends on the architecture but also on the constituent materials. The materials
\end{abstract}


electroplating, ${ }^{\mathbf{1 , 5}, 47}$ atomic layer deposition, ${ }^{\mathbf{2 3 , 4 8}}$ plasma vapor deposition, ${ }^{25}$ and dip-coating, ${ }^{27}$ to deposit films on microlattice materials. As a kind of mature technology with low cost, the dipcoating method can be used to produce high quality films over large areas, and thus, it was chosen as the preferred coating method in this study. Based on previous studies, ${ }^{12,25,26}$ in this study, silica films were deposited on the surface of diamondstructured polymer microlattices via a dip-coating method, and the resulting lightweight diamond-structured microlattice polymer/silica thin film composite materials with certain mechanical strength and thermal stability were successfully fabricated.

\section{Experimental}

\section{Fabrication of the 3D polymer microlattices}

3D polymer microlattices with a diamond structure were designed using computer aided design (CAD) software (Solid Works v2011 sp4.0) and manufactured by 3D printing. A 3D printer (MiiCraft, Young Optics Inc) based on stereolithography was used in this study. The stereolithography resin used in this study was acrylate-based EX-200 resin (Yiwu Realmaker Electronic Technolgy Co. Ltd). The size of the resulting 3D microlattice was approximately $3 \times 2 \times 1 \mathrm{~cm}^{3}$.

The process began with a photosensitive polymer resin bath. The 3D model was first converted into an STL file format and digitally sliced into a sequence of $2 \mathrm{D}$ layers, which were projected to solidify the liquid photosensitive resin. After one layer was solidified on the bottom of the tank, the object being built was recoated with a second layer of fresh resin, and then, solidification of the next layer began. These steps were repeated until the whole object was fabricated.

\section{Fabrication of the polymer/SiO $\mathrm{S}_{2}$ microlattices}

The polymer scaffolds were conformally coated with $\mathrm{SiO}_{2}$ layers via dipping-withdrawing cycles under ambient conditions. The precursor was a model glass of $\mathrm{SiO}_{2}-\mathrm{Na}_{2} \mathrm{O}$ (purity $>95 \%$, Haihua Co., Shandong, China) with a $\mathrm{Na}_{2} \mathrm{O}$ concentration of $29 \mathrm{~mol} \%$ and $\mathrm{SiO}_{2}$ concentration of $71 \mathrm{~mol} \%$. It has been denoted silica in the study since its main ingredient is silica. The withdrawal speed was $10 \mathrm{~mm} \mathrm{~min}{ }^{-1}$, and the dipping time was $15 \mathrm{~min}$. The polymers coated with $\mathrm{SiO}_{2}$ were dried at $80{ }^{\circ} \mathrm{C}$ using an oven for $60 \mathrm{~min}$ in air after each coating was finished. The thickness of the $\mathrm{SiO}_{2}$ layers was controlled by repeating the cycle from dipping to heat treatment. In this study, to ensure that the densities of the microlattice materials are within the density range of lightweight materials, we coated the material with 1-3 layers.

\section{Fabrication of the hollow-tube $\mathrm{SiO}_{2}$ microlattices}

Hollow-tube $\mathrm{SiO}_{2}$ microlattices were obtained by calcining the polymer $/ \mathrm{SiO}_{2}$ microlattices to remove the polymer template using a tube furnace (RT 50-250, Nabertherm, Germany). The polymer $/ \mathrm{SiO}_{2}$ microlattices were heated to $500{ }^{\circ} \mathrm{C}$ at a heating rate of $10{ }^{\circ} \mathrm{C} \mathrm{min}{ }^{-1}$ and kept at this temperature for $120 \mathrm{~min}$ to completely remove the polymer template under a nitrogen atmosphere. The calcination temperature depends on the thermal decomposition temperature of the template.

\section{Characterization and performance testing of the microlattice materials}

Environmental scanning electron microscopy (ESEM, FEI Quanta-250 FEG) was conducted to investigate the surface morphology and measure layer thickness of the resultant microlattices at an acceleration voltage of $10 \mathrm{kV}$.

X-ray diffraction (XRD) (D/MAX-1200, Rigaku Denki Co. Ltd, Japan) was used to identify the phase composition present in the silica layer using $\mathrm{Cu} \mathrm{K} \alpha$ radiation $(\lambda=1.5406 \AA)$ at $40 \mathrm{kV}$ and $30 \mathrm{~mA}$ in the $2 \theta$ range of $10-80^{\circ}$.

Energy-dispersive X-ray spectrometry (EDS) was also used to analyze the composition of the inorganic $\mathrm{SiO}_{2}$ coating of the polymer $/ \mathrm{SiO}_{2}$ microlattices.

TGA measurements were used to characterize the thermal stability of the polymer/silica composites in terms of their thermal degradation under a nitrogen atmosphere at a heating rate of $10{ }^{\circ} \mathrm{C} \mathrm{min}^{-1}$ and to evaluate the effect of the silica films on the degradation of the matrix.

Compression tests were performed using a servo-electric INSTRONR 5565 frame with a $5 \mathrm{kN}$ load cell controlled using the Bluehill 2.0 software. All the microlattices were tested between the compression plates at a loading displacement rate of $0.5 \mathrm{~mm} \mathrm{~min}^{-1}$, and the loading area was $3 \times 2 \mathrm{~cm}^{2}$.

The compressive strength was determined using the initial peak strength.

The apparent density was calculated by measuring the weight and dimensions of the microlattices.

\section{Results and discussion}

The $3 \mathrm{D}$ polymer/SiO $\mathrm{S}_{2}$ microlattice fabricated in this study is illustrated in Fig. 1. The microlattice was designed using a series of regular diamond cell connected at their vertices. Each diamond cell was made up of four $2 \mathrm{~mm}$-long and $0.6 \mathrm{~mm}$ diameter struts intersecting at the angle of $109^{\circ} 28^{\prime}$ (Fig. 1a-c). The length of a strut was determined as node-to-node distance $(L)$ and the diameter of a strut was defined as the average diameter $(D)$. The strut diameter of the polymer/SiO $\mathrm{S}_{2}$ was in accordance with that of the design (Fig. 1e). Fig. 1f shows a coating thickness $(t)$ of $10.1 \mu \mathrm{m}$. The coating was uniform, as observed in Fig. 1e and f. Fig. $1 \mathrm{~g}$ shows the hollow-tube $\mathrm{SiO}_{2}$ microlattice, whose density is only $14.7 \mathrm{~kg} \mathrm{~m}^{-3}$, which belongs to ultralight class of materials and can be fully supported on a dandelion. The average diameter of the hollow-tube $\mathrm{SiO}_{2}$ was about $547 \mu \mathrm{m}$, which was lower than that of solid $\mathrm{SiO}_{2}$, and the $\mathrm{SiO}_{2}$ film was not as uniform as solid $\mathrm{SiO}_{2}$ due to the slight shrinkage that occurred after the thermal treatment. The thickness was unchanged for the hollow-tube $\mathrm{SiO}_{2}$ microlattice when compared with that of the solid $\mathrm{SiO}_{2}$ microlattice (Fig. 1i).

The XRD patterns show that all the samples exhibit the same peak at around $24^{\circ}$, which corresponds to amorphous silica, indicating that the main constituent of the coating layers is amorphous $\mathrm{SiO}_{2}$ (Fig. 2a). ${ }^{49}$ EDS shows that the layer 
(a)
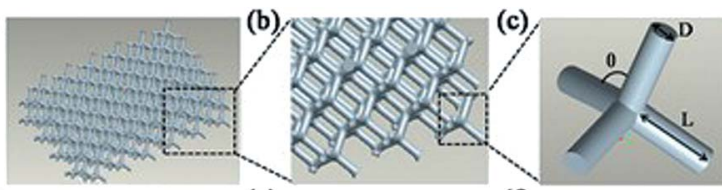

(d)
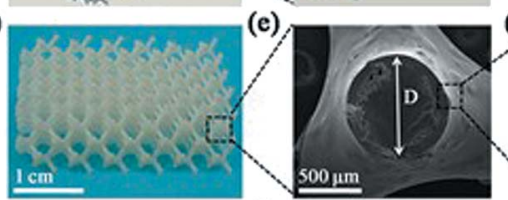

(g)

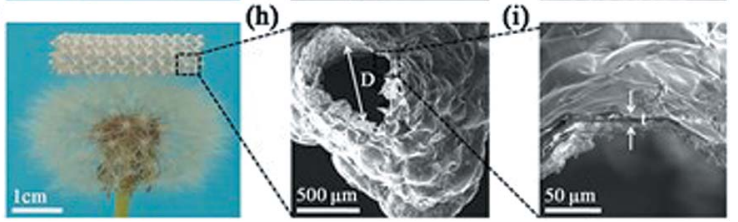

Fig. 1 The architecture of the polymer $/ \mathrm{SiO}_{2}$ microlattices: (a-e) CAD images of the diamond structure design: (a) the diamond-structured microlattice; (b) a magnified section of (a); (c) the unit cell; (d) a digital image of the 3D printed polymer microlattice coated with $\mathrm{SiO}_{2}$ via dipcoating; and (e) an SEM image of a strut in (d). (f) An SEM image of the layer thickness of a strut in (d). (g) A digital image of the hollow-tube $\mathrm{SiO}_{2}$ microlattice $\left(\rho=14.7 \mathrm{~kg} \mathrm{~m}^{-3}\right)$ supported on a dandelion. (h) An SEM image of a strut of (g). (i) An SEM image of the layer thickness of a strut in (h)

composition is $71 \% \mathrm{SiO}_{2}$ and $29 \% \mathrm{Na}_{2} \mathrm{O}$ (Fig. 2b). A small amount of the element $\mathrm{C}$ present in the EDS (Fig. 2b) may be derived from the polymer core of the polymer/ $/ \mathrm{SiO}_{2}$ microlattices. The element $\mathrm{C}$ presented in Fig. $2 \mathrm{c}$ was higher than that observed in Fig. 2b, which might be derived from the calcined products of the polymer template.

The stress-strain curves of the pure polymer, polymer/silica composites, and hollow-tube silica microlattice material are shown in Fig. 3. It can be seen that the compression strength of the pure polymer microlattice is $205 \mathrm{kPa}$, and the compression stress of the polymer/silica composites with different coating thicknesses of silica film $(10.1 \mu \mathrm{m}, 18.3 \mu \mathrm{m}$, and $23.6 \mu \mathrm{m})$ is
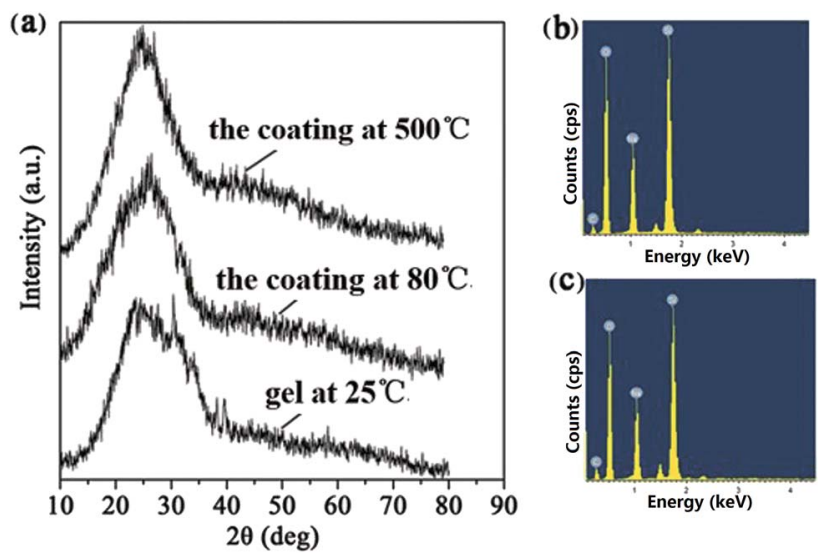

Fig. 2 (a) The XRD patterns obtained for $\mathrm{SiO}_{2}$ gel at $25^{\circ} \mathrm{C}$, the $\mathrm{SiO}_{2}$ coating dried at $80^{\circ} \mathrm{C}$ and the $\mathrm{SiO}_{2}$ coating calcined at $500^{\circ} \mathrm{C}$. (b) The EDS patterns of the polymer $/ \mathrm{SiO}_{2}$ microlattices. (c) The EDS patterns of the hollow-tube $\mathrm{SiO}_{2}$ microlattices.

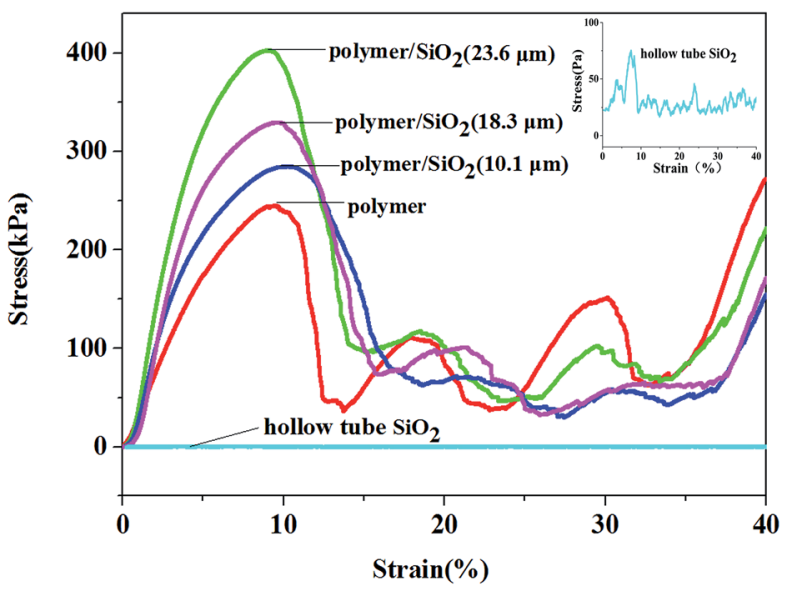

Fig. 3 The stress-strain curves obtained for the polymer, polymer/ $\mathrm{SiO}_{2}$ composites, and hollow tube silica microlattices. The magnification curve obtained for the hollow tube silica microlattice is in the top right corner.

higher than that found for the pure microlattice and far higher than that of the hollow-tube silica microlattice material. The compressive strengths of the coated microlattices are higher than that of the pure polymer microlattice because silica is stiffer than EX-200 polymer and carries the bulk of the externally applied load. The compressive strength of the polymer/ $/ \mathrm{SiO}_{2}$ microlattices increases significantly upon increasing the thickness of the coating. When the coating thickness was $10.1 \mu \mathrm{m}$, the maximum compressive strength was $286 \mathrm{kPa}$, which was 1.40 times that of the pure polymer microlattice. When the coating thickness was $18.3 \mathrm{~m}$, the maximum compressive strength was $339 \mathrm{kPa}$, which was 1.65 times that of the pure polymer microlattice. The compressive strength of the hybrid microlattices increased to $402.6 \mathrm{kPa}$, which was 1.97 times that of the pure polymer microlattice, when the coating thickness was $23 \mu \mathrm{m}$. In addition, it was demonstrated that the mechanical properties of the microlattices could be significantly enhanced at a lower density by introducing $\mathrm{a} \mathrm{SiO}_{2}$ coating. The reinforcement mechanism can be considered as the stiff $\mathrm{SiO}_{2}$ coating carrying the compressive forces, whereas the light polymeric core serves to resist early face cracking and improve the toughness. The compressive strength of the hybrid structures primarily depends on the thickness of the coating, which is the only variable factor, because the lattices possess the same structure including geometric configuration and elemental size. However, the strength of the polymer $/ \mathrm{SiO}_{2}$ composites increases to just less than twice than that of the pure polymer; if we optimize the related parameters, we can obtain a higher mechanical strength. This is one of our goals in our further research to use an ideal oxide precursor with better mechanical properties and obtain composites with obvious mechanical properties. Furthermore, the hierarchy has an important effect on the strength; thus, the increased thickness of the $\mathrm{SiO}_{2}$ coating leads to an increase in the strength of the polymer/ $/ \mathrm{SiO}_{2}$ microlattices.

All samples exhibit a similar mechanical response to compression, as shown in Fig. 3, due to the chosen geometry 
Table 1 The density and mechanical parameters of the polymer, polymer/silicon oxide composites, and hollow-tube $\mathrm{SiO}_{2}$

\begin{tabular}{|c|c|c|c|c|}
\hline Polymer & 0 & 85.5 & 203.8 & 2.384 \\
\hline Polymer/SiO ${ }_{2}$ & 18.3 & 115.09 & 336.5 & 2.924 \\
\hline Polymer/SiO ${ }_{2}$ & 23.6 & 122.46 & 403.2 & 3.293 \\
\hline Hollow-tube $\mathrm{SiO}_{2}$ & 10.1 & 14.7 & 0.090 & 0.006 \\
\hline
\end{tabular}

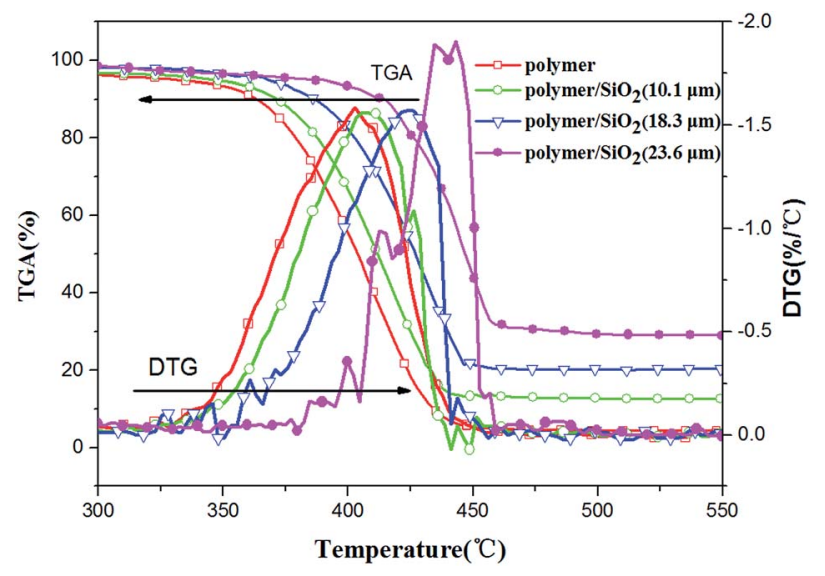

Fig. 4 The TGA and DTG curves obtained for the polymer/SiO 2 composites compared with the pure polymer.

and architecture. Generally, the samples deformed elastically over the first $3-8 \%$ strain due to the low densities and long slender trusses of the diamond structures, followed by a peak of stress between $8 \%$ and $10 \%$ strain, which corresponds to buckling of the top and bottom layers of the cells. After this peak, the stress declines rapidly before it increases again. This suggested that the structure was fully collapsed sequentially as the unit cells buckled layer by layer. Then, the structure of the polymer and polymer/ $\mathrm{SiO}_{2}$ composites was totally destroyed, and they just simply stacked together; thus, the stress strength of the polymer and polymer $/ \mathrm{SiO}_{2}$ composites had no discipline, and there was no comparability between them after their collapse.

The compressive strength of the hollow-tube $\mathrm{SiO}_{2}$ microlattice was about $90 \mathrm{~Pa}$, which was far lower than that found for the polymer $/ \mathrm{SiO}_{2}$ microlattices. Therefore, the polymer $/ \mathrm{SiO}_{2}$ composite microlattices exhibit better mechanical performance than the pure polymer lattice and hollow-tube $\mathrm{SiO}_{2}$ microlattice. The parameters and apparent densities are provided in Table 1.

To investigate the thermal stability of the polymer and polymer/SiO $\mathrm{S}_{2}$ composites with different coating thicknesses of the silica film $(10.1 \mu \mathrm{m}, 18.3 \mu \mathrm{m}$, and $23.6 \mu \mathrm{m})$, TGA and DTG were conducted. The materials were heated to $800{ }^{\circ} \mathrm{C}$ from room temperature. It was obvious that all the samples degraded between $300{ }^{\circ} \mathrm{C}$ and $550{ }^{\circ} \mathrm{C}$. This temperature range was chosen for analysis. The TGA and DTG curves obtained for all the samples are shown in Fig. 4, and the corresponding TGA parameters are given in Table 2. For the polymer/silica composites, as shown in Fig. 4 and Table 2, the thermal degradation temperatures, such as the initial temperature of degradation ( $\left.T_{\text {onset }}\right)$, the degradation temperature at $50 \%$ weight loss $\left(T_{0.5}\right)$, and the degradation temperature at maximum weight loss rate $\left(T_{\max }\right)$, increase continuously and dramatically as a function of the silica coating thickness. The maximum improvement in $T_{\text {onset }}, T_{0.5}$, and $T_{\max }$ was $59.58{ }^{\circ} \mathrm{C}$, $43.23^{\circ} \mathrm{C}$, and $37.72{ }^{\circ} \mathrm{C}$, respectively. The maximum weight loss rate $\left(V_{\max }\right)$ given in Table 2 remained hardly unchanged for polymer/ $/ \mathrm{SiO}_{2}(10.1 \mu \mathrm{m})$ and polymer $/ \mathrm{SiO}_{2}(18.3 \mu \mathrm{m})$ when compared with the case of the pure polymer, but increased obviously for polymer/ $\mathrm{SiO}_{2}(23.6 \mu \mathrm{m})$; this might indicate that the thermal degradation of the polymer was accelerated by the thicker coating of $\mathrm{SiO}_{2}$. The residue at $800{ }^{\circ} \mathrm{C}$ increased from $4.53 \%$ to $29.38 \%$ and remained unchangeable above $500{ }^{\circ} \mathrm{C}$; this suggested that the polymer was almost completely decomposed in the atmosphere at $500{ }^{\circ} \mathrm{C}$ and the residue was mainly silica. In view of these results, the thermal stability of the polymer $/ \mathrm{SiO}_{2}$ composites increased, and the thermal stability was enhanced upon increasing the thickness of the silica coating.

In summary, we have demonstrated a feasible method for the synthesis of lightweight diamond-structured microlattice polymer/silica thin film composite materials by combining the

Table 2 The thermal stability parameters of the pure polymer and polymer $/ \mathrm{SiO}_{2}$ composites

TGA results

\begin{tabular}{|c|c|c|c|c|c|}
\hline Sample & $T_{\text {onset }}\left({ }^{\circ} \mathrm{C}\right)$ & $T_{0.5}\left({ }^{\circ} \mathrm{C}\right)$ & $T_{\max }\left({ }^{\circ} \mathrm{C}\right)$ & $V_{\max }\left(\%\right.$ per $\left.{ }^{\circ} \mathrm{C}\right)$ & $\begin{array}{l}\% \text { Residue } \\
\text { at } 800{ }^{\circ} \mathrm{C}\end{array}$ \\
\hline Polymer & 307.6 & 402.6 & 410.1 & 1.59 & 4.5 \\
\hline Polymer/SiO $2(10.1 \mu \mathrm{m})$ & 332.9 & 411.1 & 418.6 & 1.54 & 12.8 \\
\hline Polymer/SiO $2(23.6 \mu \mathrm{m})$ & 367.1 & 445.8 & 445.8 & 1.91 & 29.4 \\
\hline
\end{tabular}


methods of $3 \mathrm{D}$ printing and dip-coating. With regard to the thickness of the coating, the polymer/silica lattices exhibits higher strength than the pure polymer lattice and hollow-tube $\mathrm{SiO}_{2}$ lattices. The mechanical properties of the obtained composite microlattices improved upon increasing the thickness of the $\mathrm{SiO}_{2}$ coating. When the coating thickness was $23.6 \mu \mathrm{m}$, the compressive strength of the hybrid microlattices approached 402.6 $\mathrm{kPa}$, which was 1.97 times that of the pure polymer microlattice. The corresponding density was $122.46 \mathrm{~kg} \mathrm{~m}^{-3}$, and the specific compressive strength was $3.293 \mathrm{kPa} \mathrm{m}^{3} \mathrm{~kg}^{-1}$. This study enables the mechanical properties of the polymer microlattices to be improved significantly within relativity low densities. Moreover, the thermal stability of the polymers increased with the silica coating, and the thermal stability of the polymer/silica thin film composites enhanced with an increase in the thickness of the $\mathrm{SiO}_{2}$ coating. When the coating thickness was $23.6 \mu \mathrm{m}$, the maximum improvement for $T_{\text {onset }}, T_{0.5}$, and $T_{\text {max }}$ were $59.6{ }^{\circ} \mathrm{C}, 43.2{ }^{\circ} \mathrm{C}$, and $37.7{ }^{\circ} \mathrm{C}$, respectively. Hollowtube $\mathrm{SiO}_{2}$ microlattices were also fabricated by calcining the polymer template at high temperatures, and the mechanical property test was carried out. The polymer/silica composites microlattices are expected to have a wide range of applications in the weight reduction of space vehicles, sound insulation materials, and so on.

\section{Conflicts of interest}

There are no conflicts to declare.

\section{Acknowledgements}

The authors gratefully acknowledge the financial support provided by the National Natural Science Foundation of China (Project Number: 51372010).

\section{Notes and references}

1 L. Salari-Sharif, T. A. Schaedler and L. Valdevit, J. Mater. Res., 2014, 29, 1755.

2 L. Wu, W. Li, P. Li, S. Liao, S. Qiu, M. Chen, Y. Guo, Q. Li, C. Zhu and L. Liu, Small, 2014, 10, 1421.

3 J. Bian, Prog. Mater. Sci., 2001, 46, 559.

4 Z. Xu, H. Sun and C. Gao, APL Mater., 2013, 1, 030901.

5 T. A. Schaedler, C. J. Ro, A. E. Sorensen, Z. Eckel, S. S. Yang, W. B. Carter and A. J. Jacobsen, Adv. Eng. Mater., 2014, 16, 276.

6 Y. Wei, X. Li, Z. Xu, H. Sun, Y. Zheng, L. Peng, Z. Liu, C. Gao and M. Gao, Polym. Chem., 2015, 6, 973.

7 V. P. Shastri, I. Martin and R. Langer, Proc. Natl. Acad. Sci. U. S. A., 2000, 97, 1970 .

8 P. Singhal, J. N. Rodriguez, W. Small, S. Eagleston, J. V. Water, D. J. Maitland and T. S. Wilson, J. Polym. Sci., Part B: Polym. Phys., 2012, 50, 724.

9 N. T. Trifale, E. A. Nauman and K. Yazawa, ACS Appl. Mater. Interfaces, 2016, 8, 35534.

10 Z. Liu, W. Chen, J. Carstensen, J. Ketkaew, R. M. O. Mota, J. K. Guest and J. Schroers, Acta Mater., 2016, 105, 35.
11 F. Côté, V. S. Deshpande, N. A. Fleck and A. G. Evans, Int. J. Solids Struct., 2006, 43, 6220.

12 Y. Gao, Y. F. Zhou, Q. L. Yang, L. Guo and L. Jiang, Progress in Chemistry, 2015, 27, 1714.

13 M. Mecklenburg, A. Schuchardt, Y. K. Mishra, S. Kaps, R. Adelung, A. Lotnyk, L. Kienle and K. Schulte, Adv. Mater., 2012, 24, 3486.

14 H. Sun, Z. Xu and C. Gao, Adv. Mater., 2013, 25, 2554.

15 G. Nystrom, M. P. Fernandez-Ronco, S. Bolisetty, M. Mazzotti and R. Mezzenga, Adv. Mater., 2016, 28, 472.

16 B. C. Tappan, M. H. Huynh, M. A. Hiskey, D. E. Chavez, E. P. Luther, J. T. Mang and S. F. Son, J. Am. Chem. Soc., 2006, 128, 6589.

17 J. Yin, X. Li, J. Zhou and W. Guo, Nano Lett., 2013, 13, 3232. 18 N. Chen and Q. Pan, ACS Nano, 2013, 7, 6875.

19 J. Xiong, R. Mines, R. Ghosh, A. Vaziri, L. Ma, A. Ohrndorf, H. J. Christ and L. Wu, Adv. Eng. Mater., 2015, 17, 1253.

20 M. G. Rashed, M. Ashraf, R. A. W. Mines and P. J. Hazell, Mater. Des., 2016, 95, 518.

21 X. Li and H. Gao, Nat. Mater., 2016, 15, 373.

22 X. Wang, Q. Guo, X. Cai, S. Zhou, B. Kobe and J. Yang, ACS Appl. Mater. Interfaces, 2014, 6, 2583.

23 L. R. Meza, S. Das and J. R. Greer, Science, 2014, 345, 1322.

24 T. A. Schaedler, A. J. Jacobsen, A. Torrents, A. E. Sorensen, J. Lian, G. R. Greer, L. Valdevit and W. B. Carter, Science, 2011, 334, 962.

25 Y. F. Zhou, C. Z. Yao, Q. L. Yang, L. Guo and L. Jiang, Adv. Eng. Mater., 2016, 18, 236.

26 J. Xu, Y. Gao, H. Huang, Q. L. Yang, L. Guo and L. Jiang, Sci. China: Chem., 2016, 59, 1632.

27 A. J. Jacobsen, S. Mahoney, W. B. Carter and S. Nutt, Carbon, 2011, 49, 1025.

28 T. Tancogne-Dejean, A. B. Spierings and D. Mohr, Acta Mater., 2016, 116, 14.

29 J. Rys, L. Valdevit, T. A. Schaedler, A. J. Jacobsen, W. B. Carter and J. R. Greer, Adv. Eng. Mater., 2014, 16, 889.

30 H. Wadley, Compos. Sci. Technol., 2003, 63, 2331.

31 T. A. Schaedler and W. B. Carter, Annu. Rev. Mater. Res., 2016, 46, 187.

32 S. Castilloramírez, J. Corander, P. Marttinen and M. Wang, Rapid Prototyp. J., 2012, 18, 49.

33 Q. Zheng, S. Ju and D. Jiang, Compos. Struct., 2014, 109, 23. 34 D. A. Türk, F. Brenni, M. Zogg and M. Meboldt, Mater. Des., 2017, 118, 256.

35 J. Shin, R. S. Sandhu and G. Shih, J. Digit. Imag., 2017, 30, 572.

36 W. Chen, K. Soshu and M. Yoshinari, J. Am. Ceram. Soc., 2007, 90, 2078.

37 K. Sun, P. Xie, Z. Wang, T. Su, Q. Shao, J. Ryu, X. Zhang, J. Guo, A. Shankar, J. Li, R. Fan, D. Cao and Z. Guo, Polymer, 2017, 125, 50.

38 K. Sun, Z. Zhang, R. Fan, M. Chen, C. Cheng, Q. Hou, X. Zhang and Y. Liu, RSC Adv., 2015, 5, 61155.

39 K. Sun, R. Fan, Y. Yin, J. Guo, X. Li, Y. Lei, L. An, C. Cheng and Z. Guo, J. Phys. Chem. C, 2017, 121, 7564.

40 P. Xie, K. Sun, Z. Wang, Y. Liu, R. Fan, Z. Zhang and G. Schumacher, J. Alloys Compd., 2017, 725, 1259. 
41 K. Sun, Z. D. Zhang, L. Qian, F. Dang, X. H. Zhang and R. H. Fan, Appl. Phys. Lett., 2016, 108, 061903.

42 J. Bauer, S. Hengsbach, I. Tesari, R. Schwaiger and O. Kraft, Proc. Natl. Acad. Sci. U. S. A., 2014, 111, 2453.

43 K. Tushtev, M. Gonsior, M. Murck, G. Grathwohl and K. Rezwan, Adv. Eng. Mater., 2014, 16, 156.

44 C. A. Wang, Y. Huang, Q. Zan, H. Guo and S. Cai, Mater. Sci. Eng., C, 2000, 11, 9.

45 M. Ashby, J. Am. Ceram. Soc., 2011, 94, s3.
46 L. J. Bonderer, A. R. Studart and L. J. Gauckler, Science, 2008, 319, 1069.

47 A. Torrents, T. A. Schaedler, A. J. Jacobsen, W. B. Carter and L. Valdevit, Acta Mater., 2012, 60, 3511.

48 X. Zheng, H. Lee, T. H. Weisgraber, M. Shusteff, J. DeOtte, E. B. Duoss, J. D. Kuntz, M. M. Biener, Q. Ge, J. A. Jackson, S. O. Kucheyev, N. X. Fang and C. M. Spadaccini, Science, 2014, 344, 1373.

49 V. Malinovschi, A. Marin, M. Mihalache and I. Iosub, Surf. Coat. Technol., 2016, 296, 96. 